\title{
La Revisión en el Procedimiento Penal
}

\section{Por GUILLERMo VELAOCHAGA MIRANDA}

1.--Introducción.

2.-Doctrina.

a) La tesis de la incontrovertibilidad del principio de la cosa juzgada;

b) La tesis de la primacía de los derechos humanos.

3.-Naturaleza y definición del recurso.

4.-Objeto.

5.--Motivos.

6.-Sujetos.

7.-Procedimiento y término.

8.-El órgano decidente y sus fallos.

9.-Efectos jurídicos de la anulación de la sentencia impugnada.

10.-Esquema histórico del recurso de revisión.

11.-Legislación Nacional y Crítica.

12. - Conclusiones.

13.-Bibliografía.

\section{1. - INTRODUCCION}

No suelen ser comunes en nuestro medio los estudios que tengan por objeto el análisis y examen de nuestra legislación procesal penal, y a esta escasez contribuye el ambiente apriorístico de frialdad y desconfianza con que generalmente son recibidas, lo cual, a mi modo de ver, es 10 que involuntariamente causa mayor daño a nuestra incipiente, tímida y aislada producción jurídica penal, y con más razón todavía en lo que se refiere a la parte adjetiva de la misma rama.

La posesión y disfrute de un modernísimo texto de legislación civil no debe dar como resultado el desmedro del interés por la otra cara del Derecho, quizás si más importante todavía, por cuanto en ella el elemento moral y espiritual se encuentran en situación de privilegio y enaltecidos como únicos guías, dejando al campo económico y mate- 
rial para que guiados también por estos privilegios constituyan el otro aspecto del Derecho que podríamos llamar "lo civil".

Me llamó fuertemente la atención durante mis estudios universitarios el conocido "extraordinario recurso de revisión", y la lectura y observación de unos cuantos textos al respecto concluyeron por decidirme a realizar el presente trabajo.

La esporádica aparición de este recurso debe conducirnos en aparente paradoja, a concederle la importancia profunda que pide su calidad de defensor de la verdad efectiva. Un descuido en este sentido causaría las pocas veces que se produjera el gravísimo mal que significa para el hombre la deshonra, y es la enormidad de esta injusticia la que, pese a la poca frecuencia de su aparición, determina la elevada valorización de la institución.

Sabidas son las dificultades de toda clase y los remedios de todo estilo que se aplican a fin de lograr con las inseguridades que-la debilidad humana prodiga, la presunción de verdad o verdad legal que conocemos usualmente con el nombre de cosa juzgada.

Frente a ella tenemos la verdad real, efectiva, indiscutible y cuando ambas no coinciden, del choque surge el fundamental y delicadísimo problema, la gran lucha del interés social de un lado, como patrocinador de la verdad legal y por lo tanto de la inviolabilidad de la cosa juzgada y del otro las exigencias comunes del interés individual y social que reclaman por boca de Hans: "el castigo del culpable y la itbertad del inocente" como razón suprema del Derecho Penal.

El medio eficaz de esta segunda posición es el recurso de que tratamos su fundamento, evolución, análisis y crítica en cuanto a nuestra legislación positiva es el objeto de esta tesis.

\section{2. - DOCTRINA}

Resulta realmente singular dar comienzo al estudio de una institución con el debate sobre sí se debe apoyar su supervivencia o su eliminación no solamente del cuerpo de leyes particular a que pertenece sino aún como institución jurídica en sí, y este debate es particularmente encarnizado en cuanto se refiere al recurso de revisión en el procedimiento penal.

El encarnizamiento aparecerá como perfectamente aceptable si se tiene en cuenta que se trata nada menos que de fijar una excepción a la majestad, casi mítica, de la cosa juzgada; la audacia de plantearle un caso de no vigencia y la consideración augusta de su incontrovertibilidad dan la razón del ardor de la discusión.

Veremos en primer lugar la tesis que sostiene la incontrovertibilidad del principio de la cosa juzgada y nos ocuparemos a continuación de la contraria que se apoya en la consideración de la primacía de los derechos humanos.

a) La tests de la incontrovertibilidad de la cosa juzgada.-El equilibrio deseable en toda sociedad exige que el fallo de las controversias judiciales reúna fundamentalmente dos características, en primer lugar que sea la fiel expresión de la verdad con lo que se asegura la justicia y en segundo lugar que tenga la estabilidad definitiva e inconmo- 
vible que garantice a dicha sociedad la no perturbación de un fallo legalmente justo.

Pero como los Jueces son seres humanos y por lo tanto susceptibles de equivocarse aún en los casos más evidentes, la característica de verdad, en realidad no viene a ser sino una presunción de verdad, pero no por eso se debe dejar de garantizar su permanencia definitiva como base en la forma ya expuesta que sostiene el orden adecuado en toda sociedad.

A estos dos efectos se refiere J. Acero cuando afirma que se les debe calificar como positivo y negativo. Positivo sería en cuanto a que por la presunción de verdad de lo discutido principian con la sentencia irrevocable las medidas definitivas de ejecución y negativo por cuanto viendo el segundo efecto de la cosa juzgada "la voluntad de la ley de que así quede" se impide para lo sucesivo la renovación del juicio.

A la cosa juzgada considerada en esta forma se le ha elevado a una categoría extraordinaria. Su inmovilidad debe permanecer a través del tiempo intocada e intocable.

La posibilidad de la existencia de un error queda, para los sostenedores de esta tesis, aplastada y reducida a polvo por la seguridad que proporciona al mantenimiento del orden social. ¿Qué puede significar el perjuicio probadamente injusto causado a un individuo si la sociedad se mantiene, y el orden no se perturba?

La verdad en este caso sólo lo es en cuanto la ampara el principio "res iudicate pro veritate habetur".

La inviolabilidad de la cosa juzgada debe mantenerse aún cuando no corresponde a la realidad.

$\mathrm{Su}$ exposición como presunción de verdad, la afirma Pothier al decir que "la autoridad de la cosa juzgada hace presumir verdadero y equitativo todo lo que está resuelto en la sentencia". Es pues una presunción juris et de jure.

Un ordenamiento y explicación de las razones para mantener la inmutabilidad de la cosa juzgada nos ayudará a clarificar la exposición de esta doctrina.

En primer lugar se afirma que el remedio para evitar el mal causado por una decisión equivocada se encuentra en el establecimiento de los grados de jurisdicción que sirven de prevención y cuya constitución más complicada a medida que se avanza en los grados garantiza la exactitud del fallo final y por ende su justicia.

Pero conviene tener presente que "la reiteración del debate como único remedio procesal sólo está garantizada en determinadas condiciones de calma y discusión" (J. Acero). Y es natural que así sea, la calma es el elemento necesario, el catalizador preciso que facilita el mejor estudio de los asuntos a decidir y la discusión es el aporte múltiple de ideas expuestas desde los puntos de vista más opuestos y que contribuyen con indudable eficacia al mayor acierto en la solución dada.

Es harto conocido el principio que dice "resultará mejor ordinariamente lo meditado $\mathrm{y}$ decidido por dos o más veces que lo expresado a primera impresión", se sopesan mejor los argumentos, se entienden mejor las razones, se sale más fácilmente del error, se encuentran mejores soluciones y se llega a más seguros acuerdos. 
En segundo lugar se afirma que es preciso evitar el daño que causaría la perpetuación de los litigios.

Esta afirmación sólo es cierta en cuanto se aprecie que la perpetuación de los litigios causa efectivo daño.

Pero, ¿podría alguien afirmar que la reapertura de un juicio termtnado con sentencia pasada en autoridad de cosa juzgada, debido al hallazgo de pruebas fehacientes que evidencien indiscutiblemente la inocencia de un condenado causa un daño inevitable?, un daño irreparable?

$Y$ por último enuncian su más formidable argumento condensado en esta frase, "la inmutabilidad de la cosa juzgada es necesaria a fin de dar certidumbre y estabilidad a los derechos".

Efectivamente, se debe partir de una base lo suficientemente sólida como para que asegure a perpetuidad los derechos adquiridos por declaración del Juez. La irrevocabilidad de las sentencias es garantía del honor personal, de la seguridad del patrimonio y más aún de la libre libertad si cabe la expresión. Todo medio tendente a lograr este fin será bien acogido y debe procurarse su inclusión y amparo en la maquinaria destinada a proteger la armónica convivencia humana.

La dificultad aparece en el límite marcado por la lucha entre ese derecho común que tiene la sociedad como tal y los derechos individuales que tiene cada miembro de la colectividad como persona y los que se les quiere hacer aparecer como en una oposición irreductible, en una especie de antagonismo infranqueable, siendo así que la misma esencia de su naturaleza les hace no sólo perfectamente coherentes sino que como veremos después no cabe colisión entre ellos si se les analiza a la luz de su real sustancia y de sus elevados fines. Para terminar la parte referente a la sustentación de esta posición doctrinaria daremos una rápida visión a la cosa juzgada y sus fundamentos en general.

Dice Alcalá Zamora que el objeto del proceso es la obtención de una sentencia con autoridad de cosa juzgada, y que la cosa juzgada debe entenderse en dos sentidos. Uno, formal, que garantiza su inimpugnabilidad y otro, material, que asegura su indiscutibilidad. La impugnación debe tener pues una razón de orden formal, respecto de la sentencia materia de ella y la nueva discusión debe versar sobre la materia de ella, sobre su fondo. Tenemos pues que la imposibilidad de impugnar y de volver a debatir sobre una sentencia le dá la autoridad de cosa juzgada.

Conviene aquí señalar la diferencia entre sentencia que es ejecutoria y cosa juzgada, pues suelen ser confundidas. La diferencia estriba en que ciertas decisiones que no han quedado firmes pueden ejecutarse, como por ejemplo sucedería con la libertad provisional, pedida a pesar de la apelación pendiente.

En cuanto a lo que se debe entender por la autoridad de la cosa juzgada, ella consiste en hacer presumir verdadero y equitativo todo lo que está resuelto en la sentencia; se trata pues de una presunción juris et de jure (Pothier)

Recordando lo que hemos expuesto anteriormente sobre los efectos de la cosa juzgada que son el positivo, presunción de verdad de lo discutido y el negativo, impedimiento para la renovación del juicio, debemos anotar una observación al respecto que servirá de referencia para la sus- 
tentación de la tesis contraria, y es que lo que concluye con la cosa juzgada es toda discusión o contradicción en el mismo proceso.

Además, analizando los requisitos de la cosa juzgada recordemos también que la identidad de causa reclamada se refiere al hecho jurídico (o jurígeno según otros), fundamento del derecho ejercitado y en lo penal debe entenderse como identidad del hecho delictuoso y no simplemente de su denominación legal.

Naturalmente los partidarios de esta doctrina son los antiguos maestros seguidores de un sistema legalista frío e imperturbable, cultivadores de una sumisión irrestricta a lo decidido por la cosa juzgada. Pothier en realidad va muy lejos al decir que "una sentencia pronunciada en última instancia y en juicio contradictorio, tiene una autoridad de cosa juzgada estable y perpetua".

Es hora que pasemos a la posición opuesta que hemos dicho conocemos con el nombre de la tesis de "la primacía de los derechos humanos".

b) La tesis de la primacía de los derechos humanos.-Partiendo del momento del conflicto aparente entre los derechos de la colectividad y los derechos de los miembros que la integran, podemos definir esta tesis como la que afirma que no existe dicho conflicto entre ambos derechos por cuanto un estudio de sus naturalezas nos lleva a afirmar el escalonamiento o jerarquía que existe entre ellos y en el cual el valor más alto lo representan los derechos inmanentes de la persona: honor, libertad, vida.

El "animal social" que afirmaba Aristóteles no lleva en sí un reconocimiento de supremacía de la forma de vida que es la sociedad sobre las personas que la integran, sino todo lo contrario, expresa la aceptación de la vida en sociedad como el mejor medio del perfeccionamiento de sus componentes y como medio que es, está jerárquicamente en un grado inferior en lo que respecta a los derechos que ambos puedan tener. Luego si el interés de la sociedad se quiere hacer aparecer que está en mantener la perpetuidad e inviolabilidad de la cosa juzgada, debe estar subordinado al interés del individuo que la forma y que no reclama sino el respeto y la garantía de sus derechos, imprescindibles, al honor, a la libertad y a la vida, para lo cual la institución de la revisión llena los requisitos estrictamente necesarios.

El equilibrio pedido por Ferri entre los derechos individuales y sociales es falso y no resuelve el problema, la jerarquización de ellos en la forma expuesta y con la limitación de una estricta justicia es más real y menos dificultosa. Mayores ventajas por ser más cierto ofrece el orden jerárquico que el equilibrio cuya ruptura, fácil por las fuerzas que operan en este caso, traería el caos insalvable.

Pero hemos hablado de un conflicto aparente y esto se debe a que cn realidad no existe tal conflicto por cuanto ambos derechos para ser tales no pueden estar en oposición y ello es verdad si razonamos sobre la jerarquía de derechos de que hablamos de la cual sacamos la conclusión que el justo interés del individuo no puede redundar sino en un benefico para la colectividad.

Además, jurídicamente no existe la oposición insalvable entre la cosa juzgada y el recurso de revisión. 
El tratadista Laurent cuyos estudios sobre la autoridad de la cosa juzgada son ampliamente reconocidos afirma sin vacilaciones que "el recurso extraordinario no es obstáculo a la cosa juzgada".

"La ley dice J. Acero, al hablar de la irrevocabilidad de la cosa juzgada sólo puede referirse a una inatacabilidad relativa dentro de la jurisdicción local, por agotamiento de recursos ordinarios y comunes, pero nó de los extraordinarios ni de distinto fuero".

$Y$ añáde Chiovenda: "La posibilidad de recursos como el de revisión que son mera posibilidad a plazo incierto y resultado remoto no tiene fuerza para poder aplazar la eficacia de lo ya decidido" y de ello desprendemos la falta absoluta de antagonismo entre el recurso de revisión y la veneración de la cosa juzgada. Es una posibilidad hipotética, tanto como lo es la posibilidad del error judicial que le dá origen. vino.

El error es patrimonio humano y la infalibilidad es patrimonio di-

"El objeto de la sentencia que está sujeta sólo a tales eventos, como el de la revisión, añade Acero, está normalmente destinada a servir de un modo definitivo como afirmación de la voluntad de la ley".

Ahora bien, ¿toda la sentencia tiene autoridad de cosa juzgada? Sólo la parte dispositiva de ella tiene tal categoría, y prueba de esto, siguiendo a Acero, está en que el "Juez cuando razona no representa al Estado, lo representa en cuanto afirma su voluntad".

No es posible pues justificar la aplicación a "outrance" de la cosa juzgada, los requisitos para su revisión comprueban esto y son: la fundamentación en hechos y la salvaguarda de los derechos individuales y sociales.

Profundizando un poco en los medios de impugnación aparecen sólidas y claras razones en favor de la tesis que sostenemos.

La escuela italiana por boca de Florián define como medio de impugnación: "el acto del sujeto procesal orientado a anular o a reformar jurisdiccionalmente una resolución anterior mediante un nuevo examen, total o parcial de la causa por el mismo Juez $u$ otro diferente o un juez superior". No dá esta definición el motivo por el cual el sujeto procesal se decide a pedir la anulación o reforma de la resolución.

Alcalá Zamora la define como "actos procesales de las partes dirigidos a obtener un nuevo examen total o limitado a determinados extremos, y un nuevo proveímiento acerca de una resolución judicial que el impugnador no estima ajustada a Derecho, en el fondo o en la forma, o que reputa errónea en cuanto a la fijación de los hechos".

El desarrollo de esta definición agota las posibilidades de los medios de impugnación y casi escapa por su extensión y detalle a las características de una definición, pero es completa si no breve. Observamos que el presupuesto general es un perjuicio, un daño causado a las partes y que según el mismo Alcalá Zamora para la escuela italiana se trata de un gravamen.

La definición dada por los alemanes es más simple en su expresión, dá la idea de la institución en su esencia y no con el desmenuzamiento del profesor español. Para ellos "es un medio jurídico (Rechtsmittel) de que disponen las partes para que el posible error o injusticia cometido por el juzgador sea subsanado". 
Dos ejemplos más nos harán ver que si las palabras son distintas, la idea es casi única a través de las diversas definiciones. Wetzell sostiene que recurso "es la pretensión de una parte para que se modifique una resolución judicial que dada su posición respecto de la parte contraria le resulta desfavorable"."

Y por último otros, usando la terminologia española (citados por Alcalá Zamora) opinan por definirlos como "remedios legales mediante los cuales la persona afectada por una decisión judicial puede impugnarla como equivocada", la expresión "remedios legales" caracteriza al lenguaje jurídico español y tipifica esta definición.

El "error", la "injusticia", "la disposición desfavorable", y la "equivocación" que son la base de estas definiciones tienen su fundamento en la falibilidad humana y esa es la razón de ser de los medios impugnativos, falibilidad que la aumenta o en todo caso la engendra, la ignorancia, el error, la violencia, la ofuscación, etc., y por lo tanto clama por todo un sistema que asegure o cuando menos regule la normal evacuación de decisiones justas en lo posible. Tienden pues a obtener esta seguridad y el clima de "calma y discusión" que la favorece, los diversos medios imaginados en la evolución jurídica procesal del mundo entero. $\mathrm{Y}$ así, someramente, vemos que se preocupan los pueblos por una buena elección de jueces, con características morales intachables, que se origina la recusación que ampara contra los jueces sospechosos de parcialidad, que se crean los tribunales colegiados para la primera instancia los que aportan la garantía de un opinión basada en la suma de pareceres fundados, y por último el sistema impugnativo en general que hemos analizado rápidamente.

Como el recurso de revisión está dentro del sistema impugnativo en general revisaremos rápidamente los alcances de éste y el problema de su extensión que es vital para el estudio a fondo de la revisión.

El objeto o finalidad del proceso no es perpetuar estados de incertidumbre jurídica sino por lo contrario, poner fin a ellos, luego la vía impugnativa no puede durar indefinidamente. El problema surge en la fijación del límite.

El gran tratadista Carnelutti lo enfoca certeramente al preguntar "entre la necesidad de certeza por un lado y la de justicia por el otro, ¿cuál es el límite?"

Históricamente han habido dos criterios: "el de la doble conforme y aún de la triple conforme que fué reemplazado y eliminado por el segundo o sea el de la "superior prevaleciente" que tiene como punto de partida la irreformabilidad de la resolución por parte del juzgador que la dictó.

Pero la trasmisión del juicio del inferior al superior se hace mediante un medio de impugnación que hace reaparecer el problema al preocuparnos con la extensión ilimitada de recursos.

La certeza absoluta reclamada por Voltaire se hace imposible ante las consideraciones de la falibilidad humana; a mi parecer, la admisión ilimitada de recursos se encuentra restringida únicamente por la paralela cantidad de requisitos y condiciones para plantearlos y que culminan con la revisión.

Generalmente como condiciones para el otorgamiento de recursos se establece que sólo se pueden utilizar en el número establecido en la 
ley, en el género previsto por la misma y en los términos establecidos, para las categorías de resoluciones suceptibles de ellos y con los requisitos de promoción necesarios.

Tan es así que algunos autores especifican que este recurso debe entablarse siempre en segunda instancia (Gregorio Corellano).

Expuesta pues y probada la tesis que sostiene la supremacía de los derechos humanos y su no oposición frente a la cosa juzgada, estudiados brevemente, pues no son el objeto principal de este trabajo, los medios impugnativos y sus requisitos para promover a la certeza y justicia anheladas, es hora de que entremos en el estudio propiamente dicho de la institución misma o sea el estudio del extraordinario recurso de revisión.

\section{4. - NATURALEZA DEL RECURSO Y SU CLASIFICACION}

La revisión aparece en la legislación civil y en la penal.

La revisión civil según Carnelutti tiene su fundamento en las anomalías del procedimiento lo que la diferencia de la casación civil que se basa en el error del Juez.

Pueden ser motivo de estas anomalías la actividad anómala del Juez, ya sea por no atenta como por no honrada, o bien la actividad anómala de las partes que causa perjuicio a una parte o a un tercero y por último la falta o falsedad de las pruebas.

Esta visión del cuadro de la revisión civil nos ayudará a comprender la revisión penal. A diferencia de lo que ocurre en materia civil donde siempre hay dos interesados en la resolución, en materia penal se encuentran la sociedad y el condenado y por eso, dice Corellanos "la ley no atribuye a la sentencia en materia penal el mismo efecto cerrado en cuanto a la cosa juzgada que se ha establecido para la materia civil".

Generalizando sobre esto, tenemos opiniones que toman el asunto desde un punto de vista demasiado amplio y así el profesor chileno Urrutia Salas en un reciente artículo afirma que la sentencia judicial, cualquiera que ella sea, se impugna mediante los recursos extraordinarios, siguiendo a Florián en cuanto para éste la característica de los recursos extraordinarios es la de ir contra sentencias ejecutoriadas, y expresa el maestro chileno que son dos tipos de recursos: "1) es de casación y 2) el de revisión que se concede contra las sentencias ejecutoriadas para anular los fallos ganados fraudulentemente, por cohecho o prevaricación del Juez, por fundarse sólo en testigos declarados falsos o sólo en documentos falsos o en contra de otra sentencia pasada en autoridad de cosa juzgada". Esta revisión tendría un plazo para interponerse de un año, en lo civil, contado a partir de que quede ejecutoriada la sentencia y en lo penal no tendría plazo.

No estamos de acuerdo con la tesis que sostiene la igualdad absoluta entre la revisión en lo civil y lo penal. No nos extenderemos mucho sobre este punto por tocar sólo tangencialmente a nuestro objeto.

Gregorio Corellano tiene razón cuando afirma que por la diferencia entre los sujetos procesales la cosa juzgada tiene efectos distintos en lo civil y en lo penal y es de la consideración de la cosa juzgada de donde nace la correcta apreciación de la revisión, volvemos a la afirmación repetida de que la lucha de intereses individuales exige una conclusión 
irrevocable porque existe el interés social que así lo demanda, pero la exigencia del interés de la sociedad frente a un interés individual no tiene esa característica, no hay un interés que esté al margen de ellos y su lucha es la suprema disputa que no admite plazo ni consideraciones de verdades legales o presuntas. Ellas no tienen cabida frente a los hechos probados, frente a la verdad efectiva.

Expuesta su diferencia con la revisión en lo civil entremos al análisis de la naturaleza de la revisión en lo penal.

Hemos probado que la sentencia firme no es irrevocable en modo absoluto, Florián lo expresa en frase completa "la exigencia de que la sentencia sea conforme a la realidad lo más posible es más fuerte que su perfectibilidad formal".

El punto de partida es la irreformabilidad de la resolución por parte del juzgador que la dictó.

Contra las sentencias firmes existen dos tipos de medios de impugnación, los ordinarios, que afectan todo el proceso y pueden interponerse por cualquier motivo, como por ejemplo, la apelación, y los extraordinarios, que sólo se pueden interponer por motivos específicos taxativamente determinados por la ley, y estos son la casación y la revisión.

Creemos con Florián que más racional es considerar recurso extraordinario el que va dirigido contra la cosa juzgada.

La finalidad de los dos únicos recursos extraordinarios es el beneficio del acusado, ambos están frente a la cosa juzgada y su diferencia consiste en que mientras la casación en interés de la ley corrige los errores de derecho, la revisión corrige los errores de hecho.

Aclarando estos conceptos decimos que la casación tiene aplicación en el caso de infracción de la ley o de quebrantamiento de forma.

Según el Código de Buenos Aires, llamado el Código para la Capital, es un recurso contra las sentencias pasadas en autoridad de cosa juzgada cuando aparezcan las circunstancias de hecho texativamente enumeradas en la ley. Se diferencia pues de la casación en que ésta no procede ni contra sentencias firmes, ni frente a motivos de hecho.

Tenemos pues que la revisión es un recurso extraordinario que se concede contra las sentencias firmes (ejecutoriadas según Urrutia Salas) cuando se hayan fundado en un notorio error de hecho que aparezca taxativamente enumerado por la ley.

Es un recurso establecido en beneficio del condenado y no atenta contra la cosa juzgada por cuanto ésta sólo es inviolable en tanto que responde a una realidad.

Alcalá Zamora lo considera como excepcional por naturaleza y excepcionalísimo por sus apariciones y expresa que si funcionase con frecuencia sería "la quiebra y el fracaso rotundo de la judicatura de un Estado". En nuestra opinión no es de temer que esto suceda, la quiebra y fracaso de la judicatura no aparecería como consecuencia de la frecuencia del recurso, sino al contrario el aumento de estos casos tendría como origen una magistratura anormalmente falible y una justicia prematuramente otorgada.

Respecto de la etimología de la palabra revisión, observemos que en alemán se llama, "reapertura o reanudación del procedimiento", o sea que como dice Alcalá Zamora, se le puede considerar como recurso por cuanto la relación procesal aún está abierta. En Argentina se le con- 
sidera actualmente, siguiendo a Chiovenda, como "una acción autónoma", o sea que no es un recurso sino una demanda independiente, por cuanto para ellos, abre una acción procesal conclusa.

Nuestra idea es que se trata de una segunda o "nueva visión" (García Valdez) del proceso, de donde el nombre de re-visión y por ello cabe considerarlo como recurso, pues no se trata de una demanda independiente, ni de una acción autónoma sino de reveer el procedimiento que ha terminado con una sentencia pasada en autoridad de cosa juzgada. Esta nueva visión, a base de hechos probados y evidentes permite su fácil solución.

Carnelutti expresa que "la impugnación de la sentencia equivale necesartamente a una renovación del procedimiento" y por ello nos ratificamos en nuestro dicho.

Una cuestión difícil de resolver es la referente a la definición de una institución jurídica cualquiera. Responde generalmente al momento histórico en que se enuncia y corre el albur de la variedad en las diferentes legislaciones positivas que la introduzcan. Las diversas fuentes de un ancestro jurídico señalan múltiples matices a lo que queremos aprehender en unas palabras. La revisión no es una excepción al respecto.

Así vemos que en la ley de las partidas está definida en forma que abarca desde su naturaleza hasta los casos en que puede interponerse, naturalmente en forma primitiva pero que sin lugar a dudas representa el antecedente riguroso de la figura en España.

El catedrático sevillano Rafaél de Pina ha definido con bastante acierto la revisión expresando que es "un recurso extraordinario encaminado a anular una sentencia dictada con manifiesto error de hecho, para liberar al condenado de los efectos de una resolución injusta, o para rehabilitar su memoria si ha fallecido el interesado y procurar en su caso el castigo del verdadero culpable".

$\mathrm{Su}$ acierto estriba en la indicación como fundamento del recurso de basarse en un error de hecho y su error está en la exageración al abarcar la exigencia de castigar al verdadero culpable, lo que no es objeto propio de la revisión.

La característica del recurso de revisión está como dice Manzini en "el especial elemento ético indicado por su fin que no es meramente jurídico, o sea de anulación y sustitución de juicios materialmente injustos, sino moral de rehabilitación del individuo injustamente condenado lo que resulta visible en el caso del condenado que ha fallecido".

Resumiendo, tenemos pues que la definición de Rafaél de Pina es la más de acuerdo con la naturaleza de la figura estudiada, debiendo suprimir la referencia al castigo del verdadero culpable e incluir en lo posible una indicación más concreta sobre el elemento ético de la institución.

Esta conclusión respecto de la definición no quiere decir que se patrocine su inclusión en los cuerpos de leyes; a nuestro modo de ver, toda definición debe ser excluída de la ley, la elasticidad, requisito primordial de toda disposición contemporánea está reñida con los límites siempre de aplicación incómoda que supone una definición. 


\section{4. - OBJETO DE LA REVISION}

Sobre este punto existe una gran controversia en el sentido de si deben constituir objeto del recurso de revisión las sentencias condenatorias únicamente o si deben incluírse las absolutorias.

Como premisa debemos tener presente que por la naturaleza misma de los recursos extraordinarios, éstos se entienden establecidos a favor del procesado.

$\mathrm{Y}$ así lo afirma el prestigioso penalista Aguilera de Paz al escribir que el recurso de revisión "sólo debe beneficiar al reo para no desnaturalizar el recurso", o sea que en la esencia misma de este medio impugnativo encuentra la razón de considerarlo en favor del reo siempre no habiendo lugar para la revisión de fallos absolutorios, lo que sería contrario a la característica básicamente ética que encuentra Florián en esta materia.

El argentino Gregorio Corellano se pronuncia igualmente a favor de esta apreciación, sosteniendo que "procede siempre en beneficio del condenado y nunca en su contra".

Para Ambrosini (citado por Ferri) la revisión de fallos absolutorios es "una exageración" y Casorati (idem) la encuentra "llena de dificultades".

La posición contraria está encabezada por el mismo Ferri en forma violenta pues se basa según sus propias palabras en que "no se nos alcanza que existiendo contra una sentencia favorable al acusado las mismas sospechas que dan lugar a que se revisen las sentencias condenatorias, la sociedad haya de sufrir tranquila las absoluciones y las mitigaciones indebidas de responsabilidad penal" y prosigue creyendo que "puede haber sido absuelto porque la acusación, que no tiene el don de la omniescencia y que se ve obligada a valerse de los datos suministrados por la instrucción, no conozca al tiempo del proceso un documento decisivo". Concluye pensando que "negar la revisión de sentencias absolutorias se debe a que se considera al imputado aún déspués de la condena como víctima perseguida cuya seguridad y salvación hay que procurar a toda costa".

En resumen, para Ferri, si se es justo que se reparen errores de que el condenado es víctima, es justo que se reparen los que hayan importado para la sociedad la impunidad del delincuente.

Manduca opina en idéntica forma en su tratado sobre el desarrollo científico del procedimiento penal y razona en esta forma: "si el individuo tiene el derecho de no ser condenado cuando no está probada su culpabilidad, la sociedad tiene derecho de no ver absuelto al acusado a no ser que la inocencia se demuestre por una rigurosa valuación de las pruebas" y reclama que ella no sea proclamada "por sorpresa de algún jurado distraído o pusilánime" citando a Ferri y Lombroso. Se refieren naturalmente a la revisión del veredicto del jurado. Se apoya igualmente Manduca en la declaración de Cesarini "los inconvenientes del derecho moderno no dimanan de la exorbitancia de las condenaciones sino de las absoluciones escandalosas".

Así mismo, el tantas veces mencionado Alcalá Zamora, autor de un novísimo tratado de "Derecho Procesal Penal" en unión de Levene se- 
ñala que la revisión debe admitirse en contra y a favor del reo pues "tan injusta es la absolución del culpable como la condena del inocente, exigiendo por razones obvias, un asentimiento de la institución sobre sólidas bases, y que no haya mediado prescripción.

$\mathrm{Y}$ por último, el sagaz comentarista del procedimiento penal mejlcano, Julio Acero encuentra que las mismas razones que sirven para admitir la revisión o sea, la consideración de que una pena no puede ser legítima sino cuando se impone a un culpable, la diferencia de objeto entre el Derecho Civil y el Penal, (la primacía de los intereses pecuniarios en lo civil, el contentamiento de lo civil con la verdad legal) y el errcr de creer en la infalibilidad papal de los jueces, sirven para acreditar "las exigencias del derecho de la sociedad para pedir la sanción del injustamente absuelto" y encuentra que las nuevas escuelas positivistas "desdeñan las barreras de la cosa juzgada y proclaman la imprescriptibilidad de las acciones penales".

Nuestra opinión respecto del interesantísimo problema que acabamos de plantear se inclina a favor de la admisión del recurso sólo en Ios casos de sentencias condenatorias por las razones que exponemos a continuación.

Sentamos como premisa la consideración, que es opinión de Florián, del fundamento radicalmente ético de la revisión, lo que da como consecuencia que se contemple este recurso en el sentido de que favorezca al reo.

Ferri no se equivoca en sus afirmaciones pero olvida remitirlas a la observación que acabamos de anotar, con ella quedan subsanadas las tachas que opone y afirmada, creemos, nuestra tesis.

La petición de justicia que es el sostén de Alcalá Zamora y Levene está satisfecha con la absolución del inocente, la libertad del culpable es un absurdo jurídico puesto que desde el momento que no se le halló como tal no lo es y el hallazgo de pruebas que evidencien un delito cometido por él dá perfectamente el derecho de acusarlo por dicho motivo, sin necesidad de pedir la revisión de lo ya sentenciado.

El alegato de que podría funcionar la cosa juzgada como excepción que lo favorezca no tiene apoyo sino en cuanto se considera que es la sociedad la perjudicada y hemos visto que la revisión funciona en beneficio del condenado y por razones éticas que presuponen su no aplicación en el campo de las sentencias absolutorias.

Queda pues establecido que en general el recurso de revisión sólo se concede frente a las sentencias condenatorias. Una nueva discusión surge respecto del tipo de sentencias condenatorias suceptibles de este remedio. Será permitido usarlo respecto de los casos de juzgamientos de delitos menores y de las circunstancias agravantes? Nos parece, con Florián, que sólo debe limitarse al establecimiento definitivo de dos situaciones: 1) si hubo o nó delito, considerado como hecho, y 2) si fué realizado o nó por el acusado; se cierra así el campo del ejercicio de este medio impugnativo y se evita, como quiere García Valdez, que se convierta por falta de cautela en una nueva instancia.

Entrando ya, detalladamente, en el campo del derecho positivo podemos indicar las sentencias respecto de las cuales funciona.

En primer lugar dice Florián, respecto de la sentencia de la autoridad judicial ordinaria de primera instancia o apelación que sea de 
"condena por delito" o condena "por contravención y que califique de contraventor habitual o profesional al acusado".

Esto nos parece exagerado; debe limitarse su aplicación en un sentido general a las sentencias que se hayan hecho firmes, ya que su objeto es resumiendo: verificar si el hecho se realizó o nó y si el acusado participó en él.

Para llegar a esto se debe eliminar, o mejor dicho no tomar en cuenta las diversas posibilidades que suelen ser obstáculos insalvables a otro género de recursos. No opera pues, de acuerdo con esto la sentencia que haya prescrito por cuanto, como veremus más adelante. no hay plazo para la interposición de este recurso. Tampoco es obstáculo que la condena haya sido cumplida por cuanto uno de los fines es conseguir la rehabilitación del inocente y limpiarle la mancha que le sigrifica la sentencia condenatoria. El fallecimiento del condenado, asimismo no se opone, sino al contrario es una razón más para el uso del recurso por cuanto reivindica la buena reputación del difunto y sanea la herencia moral que trasmitió a sus sucesores.

\section{5. - MOTIVOS DE LA REVISION}

Parecería natural que el recurso de revisión se concediera en todos los casos en que el condenado resultara inocente. Pero no es posible establecer en un cuerpo de leyes positivo disposición tan amplia, por cuanto atentaría contra la misma importancia del recurso. Hemos indicado ya el peligro que correría de quedar convertido en una nueva instancia y a él habría que añadir la reiteración de un debate agotador $\mathrm{y}$ sin pruebas evidentes o que permitan dilucidar rápida y eficazmente el problema.

Veremos que la tendencia actual se orienta no a la supresión sino al condicionamiento adecuado de los recursos a fin de no tergiversar su objeto y permitirles un fructífero cumplimiento de su misión. De acuerdo con esto pues, la doctrina y la práctica se han esmerado en presentar en la forma más específica posible los casos o motivos que pueden dar lugar a la presentación de este remedio legal, o a su condensación en una fórmula breve pero que cierre el camino a todo abuso de él.

Expondremos las principales opiniones y luego daremos nuestro parecer al respecto.

Según Florián, son cuatro los motivos de revisión:

Primero, la contradicción de sentencias firmes en relación con los hechos, o sea la inconciliabilidad.

En segundo lugar, en el caso de cuestiones prejudiciales sería motivo, la renovación de la sentencia del juez civil o administrativo que haya resuelto una de aquellas cuestiones y sobre la que se haya basado una sentencia penal para estimar realizado el delito. La sentencia penal debe seguir la suerte de la civil o administrativa presupuesta revocada por cuanto el hecho queda falto de un elemento constitutivo de delito. Cita como ejemplos la comprobación de la propiedad de la cosa en caso de robo y la exclusión de la validez del primer matrimonio en caso de bigamia.

En tercer lugar indica el caso de haber sido debida la condena a falsedad cometida en los autos o a otro delito y por último contempla el caso de descubrimiento después de la condena, de "nuevos hechos o 
elementos de prueba" que por sí o junto a los conocidos demuestran evidentemente la inexistencia del hecho delictuoso o excluyen terminantemente de él la intervención del condenado.

Julio Acero al criticar en el procedimiento mejicano el uso forzado que hace en la figura del indulto necesario, legalismo absurdo que suple a revisión, indica los motivos que lo autorizan y que a la larga se han limitado a cuatro.

Los exponemos, por cuanto consideramos que no existiendo la revisión en Méjico, sus funciones la llena el citado indulto neceșario. En la parte dedicada a la legislación comparada haremos la crítica de esta aberración jurídica.

1) "En primer lugar se otorga el indulto necesario cuando "la sentencia se funóó en documento o declaraciones de testigos que después de dictada fueren declarados falsos en juicio".

2) "Cuando después de la sentencia aparecieran documentos que invaliden la prueba en que descanse aquella o las presentadas al jurado y que sirvieron de base a la acusación y al veredicto".

3) "Cuando condenada alguna persona por homicidio de otro que hubiere desaparecido se presentare éste o alguna prueba irrefutable de que vive".

4) "Cuando el reo hubiere sido juzgado por el mismo hecho a que la sentencia se refiere en otro juicio en que también hubiere recaído sentencia irrevocable".

Observamos que en resumen se pueden indicar en esta forma: 1) pruebas que posteriormente resultan falsas; 2) pruebas que invalidan las anteriores; 3) supervivencia de la víctima en un homicidio; 4) sentencias contradictorias.

Según José Orano, profesor de la Universidad de Roma, las causales deberian ser:

1) Si después de sentencia irrevocable se descubre que no hubo delito, poniendo como ejemplo el caso de la urraca ladrona, presentado por Hentham.

2) Si a pesar de la sentencia condenatoria la inocencia de alguno fuere proclamada por la voz pública, lo cual sirvió como prueba en el famoso caso de Carlos Chávez, único en la jurisprudencia nacional.

3) Siempre que el condenado, por causa que no puede imputársele, no haya podido practicar todos los medios de defensa que sin saberlo existían.

4) Cuando dictada sentencia irrevocable fuere proclamado inocente uno de los supuestos condenados por los supuestos co-reos.

5) Si después de la condena declarase un informe de alienista que la enfermedad mental del condenado precedió a la sentencia y al delito.

E1 análisis de estas clasificaciones lo hacemos posteriormente.

Otro tratadista, citado por Acero, Antonio Galatea, encuentra un sinnúmero de motivos de presentación del recurso y así afirma que procede cuando: 
1) Es comprobable la corrupción de los jueces. suicidio.

2) Cuando se acredita que no se trató de un homicidio sino de un

3) Cuando se compruebe que la víctima de un homicidio falleció de muerte natural. cidio.

4) Cuando se pruebe la supervivencia de la víctima de un homi-

5) Cuando se verifica que ha habido un error matemático en las conclusiones que llevaron a la sentencia.

6) Cuando se trata de un error material.

7) Cuando se trata de un error por cambio de autos procesales.

8) Cuando posteriormente se realiza la abolición de un crimen.

9) Cuando se trata de un error científico.

10) Cuando se realiza la recuperación de lo que se creía robado.

11) Cuando se realiza la demostración de un hecho cuya existencia haga imposible la delincuencia supuesta, verbigracia la coartada.

12) Cuando la sentencia se basó en un documento declarado falso.

13) Cuando ha operado la supresión de documentos.

14) Cuando hayan habido declaraciones falsas de testigos o peritos contumaces.

15) Cuando ha mediado falsedad de un ujier que afirma no puede ser hallado un testigo.

16) Cuando ha habido condena inconciliable de un nuevo reo en rebeldía.

17) Cuando se comprueba judicialmente que existió un nuevo reo premuerto o irresponsable, o contra quien no se puede proceder.

La utilidad escasa, de esta detallada numeración estriba en la antiguedad de su proposición que da una buena pauta de la forma de considerar la revisión anteriormente.

Alcalá Zamora y Levene encuentran que procede cuando:

1) Consta que el delito fué cometido por una persona y aparecen varios acusados $\mathrm{y}$ varios condenados. tima.

2) En un caso de homicidio se acredita la supervivencia de la víc-

3) La sentencia se basó en documento que fué declarado falso después en juicio.

4) Aparecen documentos decisivos, ignorados, extraviados o detenidos por fuerza por la acusadora.

5) Una ley posterior diga que ese acto no es punible o haya disminuído su penalidad. 
Esta última causal, de disminución de la pena por ley posterior se encuentra apoyada por la opinión de Gregorio Corellano que funda su inclusión en el artículo 551 del Código de Procedimientos Criminal Argentino, a raíz de la publicación del Código Penal de ese país en 1922.

Y por último, Rafaél García Valdez, comentarista español, aprueba las causales contenidas en el Código adjetivo penal español y que adicionado por la ley Azcárate dice así:

Procederá el recurso de revisión:

“1) en los casos de sentencias contradictorias;

2) en el caso de la supervivencia de la víctima de un homicidio;

3) en el caso de prueba por sentencia firme de la falsedad de un cocumento o testigo; $\mathrm{y}$

4) cuando aparezcan nuevos hechos sobrevinientes a la sentencia que evidencian la inocencia del condenado".

En el Código de Procedimientos Penales de Guatemala se incluye una curiosa causal que lo autoriza en el caso que "el raptor condenado según el Código Penal, dé cuenta del paradero de la persona robada o apareciera ésta". Para Castellanos, su comentarista, son "casos que aducen situaciones dictadas por la razón natural".

Para poder emitir un juicio acertado sobre estas opiniones y a la vez expresar la propia es conveniente que tengamos presente ciertos puntos relativos a la naturaleza de este recurso y a su objeto.

Se trata hemos visto de un recurso extraordinario contra sentencias que han sido pactadas en autoridad de cosa juzgada, luego su importancia capital por esta característica pide que se le rodee de toda clase de seguridades que eviten tanto el abuso que representa el peligro de ser considerado como nueva instancia, como su errónea o equivocada aplicación que burlaría lastimosa y paradójicamente el ideal de justicia real que invoca.

Podemos comenzar a discriminar sobre las causales que lo pueden motivar diferenciándolas de las que sirven de fundamento para la casación y ello nos dará una primera regla para eliminar las innecesarias.

Si el objeto de la casación en interés de la ley es corregir los errores de derecho, quedan descartadas todas las causales fundadas en este motivo. $\mathrm{Y}$ entre los errores de hecho que puedan dar lugar a una sentencia equivocada podemos tomar el cuadro que para la revisión civil formula Carnelutti, naturalmente que con las modificaciones que por razón de tratarse de la revisión penal que tiene fundamentos distintos, nos hemos permitido hacer.

Carnelutti afirma que la diferencia entre la revisión civil y la casación civil, está en que aquella se funda en anomalías del procedimiento y ésta en el error del Juez.

Entre las anomalías del procedimiento encuentra que se pueden cleber a tres factores: 1) la actividad anómala del Juez que puede ser no atenta, o carente de honradez; 2) la actividad anómala de las partes que puede causar perjuicio a la otra parte o a un tercero y 3) la falta o falsedad de las pruebas que puede consistir en la falta de una prueba verdadera o en el uso de una prueba falsa. 
De este cuadro tomamos íntegramente lo referente a la falta o falsedad de las pruebas y, lo referente a la actividad anómala del Juez y de las partes, lo supeditamos a que sean originadas por manifiesto error de hecho. Vemos pues rememorando las opiniones expuestas, que la mayoría de los tratadistas están de acuerdo en que los principales motivos de la revisión se agrupan en tres tipos: los que se fundan en la falsedad sea de testigos o de documentos, los que se fundan en la supervivencia de la víctima de homicidio y los que se fundan en las sentencias contradictorias. Además generalmente como veremos en la legislación comparada se añade al final de las causales una que en realidad abarca a todas las demás, defecto que mantiene nuestro Código. En realidad aparece como si por un tardío arrepentimiento de no comprender en 3 ó 4 incisos todas las causales, se deja la válvula de escape que no otra cosa significan las frases de "toda otra prueba", "cualquier evidencia", "nuevos hechos", etc.

Nos parece que los motivos que debe estipular la ley para la fundamentación del recurso deben comprender:

1) Prueba evidente no conocida en el juicio de que no se realizó el hecho; $y$

2) Prueba evidente no conocida en el juicio de la inocencia absoluta del condenado. Fuera de estos dos casos nos parece que no cabe el recurso tanto como hemos dicho por su naturaleza como por el peligro que entraña su abuso o su colocación en manos poco cautelosas o serias.

En estos nos inclinamos por el estilo de la fórmula alemana que condensa todos los motivos al preceptuar que "siempre que se descubra un documento nuevo y surjan nuevos indicios de la inocencia, el condenado puede pedir la revision" y decimos que por el "estilo" por cuanto esta fórmula aún es peligrosa. La expresión de las dos causales indicadas más arriba tiene las ventajas de que es perfectamente doctrinaria su enunciación y además su alcance, al ser fácilmente adaptable, queda condicionado a la apreciación por quien corresponda de si realmente el motivo encuadra dentro de alguno de los dos aspectos considerados.

Como ejemplo práctico del sistema propuesto citamos la ejecutoria de la Corte Criminal de la Capital (Buenos Aires) de fecha 25 de noviembre de 1941 (Jurisprudencia Argentina - 1942 IV pág. 126) que estableció que "corresponde desestimar el recurso de revisión cuando la documentación ofrecida por el recurrente no rectifica la calificación del hecho delictuoso ni desvirtúa la responsabilidad penal del autor".

Las diversas causales propuestas por los autores citados quedan así contenidas en la fórmula propuesta; en cuanto a la detallada enumeración propuesta por Galatea su simple lectura denota su inaplicabilidad, su inclusión obedece únicamente al deseo de informar plenamente sobre la variedad de soluciones aportadas.

Con esto damos por terminado el problema referente a los motivos en los cuales se debe basar la petición de reapertura del proceso amparada en el recurso de revisión y toca a continuación, ocuparnos de las personas que pueden hacer uso de dicho recurso, lo que es materia del capítulo siguiente. 


\section{6. - SUJETOS DE LA REVISION}

Siguiendo a Florián, podemos afirmar que por tratarse de una institución de interés público y privado a la vez, son dos las categorías de sujetos que pueden hacer uso de ella.

En primer término el condenado o parientes próximos en la forma que desarrollamos a continuación y en segundo lugar el Ministerio Público "prueba del interés público inherente a la institución".

La gran mayoría de los tratadistas y casi todos los cuerpos de leyes que tratan de la revisión están de acuerdo en que ella puede ser utilizada tanto por el condenado como por su cónyuge, ascendientes, descendientes y hermanos. La idea general es de autorizar a todos los que tengan interés en el asunto, pero no es posible amplificar en estos términos el uso del recurso; opinamos por la especificación detallada de aquellos y por la inclusión como lo hace nuestro Código del tutor y del padre e hijo adoptivo. La referencia al grado de consaguinidad exigido suple la excesiva longitud que pueda tener el artículo que se ocupe de este punto. La inclusión del Ministerio Fiscal, que no es objeto de discusión por ningún tratadista, tiene su fundamento en sus mismos fines, o sea la defensa de la sociedad que se extiende a la defensa y rehabilitación de uno de sus miembros injustamente agraviado. El peligro aparece, señalado ya por García Valdez, en que para varios autores debe aplicarse el derecho hasta convertir el recurso a un carácter de acción popular. No somos de este parecer.

Poner en manos de cualquiera la interposición de un recurso que tiene un objeto tan importante y decisivo, es atentar contra sus propios fines, es facilitar el camino a consecusión de resultados adversos a los buscados. Pero no por ello debemos caer en la exageración opuesta de negarlo a los herederos. Si hemos visto las razones para otorgarlo a los que son perjudicados por la sentencia injusta en vida del condenado, mayor razón habrá a la muerte de éste para concederlo a sus herederos, en primer lugar porque nadie mejor que ellos puede reunir los requisitos exigidos para interponerlo, o sea garantías de "ecuanlmidad" y "celo" de que habla García Valdez, y en segundo lugar, porque precisamente uno de los fines de esta institución consiste en rehabilitar la honra del agraviado que es repetimos "patrimonio de los que le suceden".

No estamos de acuerdo con el temor de Garófalo (citado por Giurati) de la aparición del oficio de "delincuentes fingidos" a fin de obtener la indemnización pecuniaria que veremos más adelante. La estricta aplicación del recurso a los casos previstos por la ley y el establecimiento de las personas determinadas a las que se autoriza para interponerlo garantizan perfectamente la salvaguarda de semejante amenaza. No creemos en la facilidad de fraguar una "prueba evidente" ni en la sencillez de acreditar un parentesco y un interés fingidos; la experiencia lo ha comprobado, no se ha dado una cadena de casos como para considerar fundado dicho temor. 


\section{7. - PROCEDIMIENTO}

Surge al estudiar este aspecto del recurso de revisión la interrogante de si debe interponerse de oficio o a petición de parte.

Para unos, como Carnelutti, extendiendo en esto su apreciación de la revisión civil al campo penal, debe negarse la interposición de oficio del recurso. Alegan que el silencio de parte agraviada por la injusticia es prueba de su asentimiento de la sentencia o mejor dicho, presunción de la justicia de ésta, opinan además porque "no interest rei publica" la comprobación de la justicia del fallo y además porque "la aceptación de las partes es señal de su justicia o de la tolerabilidad de su injusticia en el sentido que la reparación no compensa el costo del procedimiento".

La tesis contraria, que es la nuestra, ampara el uso del recurso no sólo a petición de parte sino también de oficio. En la Exposición de Motivos del Código de Procedimientos en Materia Criminal se dice que "la discrepancia de opiniones se reduce a determinar a quien corresponde el derecho de pedir la revisión. Nosotros la concedemos en los casos de evidente injusticia junto con el Ministerio Público a todos los que representan el interés de la víctima" pero añade "que en el último caso (se refiere al inciso $4^{\circ}$ del artículo 365 ; cuando aparezca un hecho o se descubran documentos no conocidos en el juicio y que sean capaces de establecer la inocencia del condenado) en que la injusticia resulta de una interpretación, ese derecho sólo puede ser ejercido por uno de los Fiscales de la Corte Suprema. Esta garantía que evita las articulaciones del reo permite aceptar el recurso para todos los casos en que a juico del Fiscal, el hecho o documento descubierto demuestra el error en la sentencia". Fundamentan pues los autores del citado Código en las exigencias de garantía la atribución exclusiva del Ministerio Público en los casos contemplados en el referido inciso $4^{\circ}$. Reproduciendo estas razones, que hacemos nuestras, podemos afirmar que casi por unanimidad se encuentra aprobada e incorporada la posibilidad de interponer el recurso a petición de parte $\mathrm{y}$ de oficio. La variedad está en las causales que exigen uno $u$ otro procedimiento.

En cuanto al organismo judicial al que debe ser dirigido el recurso, algunos favorecen la idea de que sea originariamente presentada la solicitud al Ministerio de Justicia el que a su vez ordenaria al Fiscal que interponga el recurso si a su juicio hubiese el fundamento necesario. Este sistema propugnado por García Valdez no excluye la presentación de oficio por el Fiscal. A continuación el Tribunal Supremo oye por escrito tanto al Fiscal como al penado, luego se piden los autos antecedentes y el trámite se desenvuelve conforme al prescrito para la casación por infracción de la ley en la legislación española que es la comentada por este tratadista. No hay inconveniente para evacuar informe oral por parte de la defensa del penado pero no es trámite indispensable.

La sentencia naturalmente tiene el carácter de irrevocable. Observemos que la iniciación de este procedimiento es ante el Tribunal Supremo y hacemos esta anotación por cuanto para otros como Gregorio Corellano, la revisión debe ser siempre entablada en segunda instancia. 
Otra modalidad muy original por cierto es la usada en Méjico en que por no existir la revisión se hace uso de la figura del indulto necesario cuyo desarrollo procesal se verifica ante las autoridades judiciales pero cuyo otorgamiento lo concede el Ejecutivo y esta peculiaridad nace de la figura del indulto empleada como legalismo.

Comentando la legislación argentina, Alcalá Zamora y Levene hacen ver que la tramitación se realizará según el organismo que falló en definitiva. Así, si la Corte Suprema fué la que expidió la sentencia ejecutoriada a ella compete conocer del recurso planteado contra dicho faHo entendiéndose con las Cortes de Apelaciones el recurso interpuesto contra las sentencias que fueron consentidas y ejecutoriadas ante esos cuerpos.

El trámite siguiente sigue lo establecido para las apelaciones libres.

Para Florián el procedimiento debe ser idéntico al establecido para el recurso de casación ante el Tribunal Supremo pero hace hincapié en un punto especial; la facultad que tiene el Tribunal Supremo para investigar ampliamente y con el objeto de hacer un uso adecuado de esta facultad tiene amplia potestad instructora para lo que designa un magistrado especial.

Entre nosotros el Código de Procedimientos en Materia Criminal de 1922 establecía terminantemente que "la sentencia condenatoria deberá ser revisada por la Corte Suprema cualquiera que sea la jurisdicción que haya juzgado o la pena que haya sido impuesta" y este articulado se encuentra reproducido en la parte primera del artículo 361 del nuestro, novísimo Código de Procedimientos Penales de 1939, y en lo referente al trámite posterior ambas preceptúan lo mismo "el recurso deberá ser interpuesto ante la Corte Suprema acompañando los documentos que acrediten el hecho en que se funda. La Corte Suprema encomendará a dos de sus Fiscales que se informen de los hechos alegados y que dictaminen sobre la solicitud y resolverá en Sala Plena si hay lugar a que se anule la sentencia y a que se renueve el proceso. En esta audiencia no votarán los Fiscales informantes pero concurrirán para dar las explicaciones necesarias. El reo o el defensor que éste nombre debe ser oído si concurre".

En el procedimiento penal guatemalteco, la Corte Suprema debe traer todos los antecedentes; a continuación se realizarán dos audiencias, una con el Fiscal y otra con el penado y el acusador del juicio cuya revisión se trate, después de lo cual se verificarán a petición de ella las diligencias que estima necesarias procediéndose enseguida conforme a los trámites de casación.

Habiendo visto las posiciones de la doctrina y de algunas legislaciones podemos deducir que el recurso de revisión tiene como procedimiento el mismo que el exigido para la casación en los países en que ésta existe previa una iniciación especial tendente a reunir rápidamente el material de antecedentes y nuevas pruebas que permitirán resolver rápida y justicieramente el caso. En los países en los que no existe el recurso de casación el procedimiento tiene un principio igual al expresado anteriormente y por las mismas razones pasando luego al Tribunal Supremo, que puede tener cualquier denominación, a desdoblarse en la función instructora y en la resolutiva, estando uniformemente de acuerdo en conceder al reo o a su defensor la posibilidad de hacer su defensa oral. 
Nos parece que este sistema es el más adecuado; la importancia del recurso y la relativa poca frecuencia de su aparición son fuertes argumentos contra los que opinan que no merece un procedimiento especial. Recordemos que es el "recurso supremo" cuando el ejercicio de la acción penal ha terminado por medio de sentencia firme, lo que le da la categoría de extraordinario. Reclamar pues, repetimos, un procedimiento especial y en la forma que exponemos anteriormente se pone en manos de la autoridad judicial máxima la delicada función de revisar las decisiones últimas, "la facultad de rescindir sentencias injustas para sustituirlas por justas".

La información y dictamen de dos Fiscales asegura contra el abuso del recurso y con ello se cumple con lo deseado por Castellanos "la sencillez y brevedad del procedimiento atendiendo a la naturalza del recurso".

Nos parece que no debe ser permitida la formación de incidentes, ni el planteamiento de excepciones pues no se trata de una reanudación de la acción penal ya que ésta concluyó en la segunda instancia.

La casación anterior tampoco nos parece que sea motivo para no poder hacer uso del recurso pues ella tiene otro objeto como anteriormente hemos expuesto. cación.

Pero pueden aparecer diversos problemas que hagan difícil su apli-

Alcalá Zamora pregunta: si aparece un motivo de revisión mientras se sustancia un recurso de casación de fondo, ¿habrá que esperar una sentencia inútil o renunciamos a ella?

Conviene recordar que el éxito de la casación no está garantizado a priori, luego es arriesgar una denegatoria de este recurso la renuncia a la casación planteada.

En el procedimiento civil italiano existe un remedio que análogamente patrocina su introducción a lo penal el tratadista español. Se trata de la "revocazione" (contenida en el art. 395 del Código de 1940Italia) y su objeto es permitir la impugnación de sentencias que no han sido pactadas en autoridad de cosa juzgada; son sentencias meramente definitivas y así llaman a las pendientes de la casación.

No estamos de acuerdo con la nueva institución que propugna el autor citado. En primer lugar no creemos que exista problema en la situación que plantea. Si hemos establecido recurso de casación es porque efectivamente creemos que existe una causal que pueda dar lugar a. su casación y aprobación, no se trata de arriesgar un recurso $u$ otro en busca de una sentencia favorable cualquiera que sea el motivo en que se funde. La casación y la revisión tiene sus causales y la interposición de cualquiera de estos recursos no es excluyente como hemos visto, siempre que se planteen en su debido término fijado por la ley para la casación e imprescriptible para la revisión.

En segundo lugar hemos estudiado que los requisitos para la revisión son tan estrictos y deben tener una calidad de evidentes en tal grado que es fácil de antemano conocer la suerte que correrá el planteamiento del recurso.

Si la revisión exige aparentemente el sacrificio de la cosa juzgada es porque "su concepto no puede ser causa del mantenimiento de injusticias visibles o mejor dicho, claramente manifestadas"; es pues la tras- 
cen lencia de la revisión la que obliga a determinar con precisión las situsciones que la admiten.

Scbre la determinación de si la revisión es admisible en los casos que el condenado se halle cumpliendo condena, o si ha fallecido resulta inútil dar razones. La lógica más elemental lo aprueba en ambos casos, bástenos citar solamente lo expresado por Mariano Herrera sobre el triple fin del recurso: "rehabilita de la sentencia, indemniza de la condena, y acredita la inocencia".

Fn cuanto al término para interponer el recurso no hay necesidad de dar mayores razones que las expuestas para apoyar su existencia, y las analizadas para determinar su naturaleza, de las que se desprende su imprescriptibilidad.

El eminente procesalista penal Aguilera de Paz expresa que "sublevaría a la conciencia que se estableciese plazo para la revisión". Si su fin específico es evitar perjuicios injustos, a mayor tardanza en interponerlo mayores serán los daños que causa lo que obliga a contemplar la carencia de término para utilizarlo como condición inseparable de su adopción.

\section{8. - E⿱ CRGANO DECIDENTE Y SUS FALLOS ('Terminología tomada de Florián)}

La decisión del Tribunal no puede ser la misma en todos los casos de revisión, y aún varía según la aceptación o no del recurso.

Florián exige que la decisión sea en secreto y que sólo deben intervenir las dos salas de lo criminal (se refiere al procedimiento italiano) cuande se trats de contradicción de sentencia condenatoria impugnada con otra dictada por un juez especial.

Considera además tres clases de decisiones: 1) la inadmisibilidad, que se dá en los casos de faltar los presupuestos para la revisión, 2) la desestimación cuando se encuentra que el recurso es infundado y 3) la revisión y anulación de la sentencia que puede ser con "rinvío" o sin él. Anslicomo eto. No hay "xinvio" cuando es evidente la inexistencia del hecho material que condena y siempre que el hecho nuevo haya sido probado y además en los casos que el condenado haya fallecido.

En cambio el "rinvío" aparece por el juicio rescisorio cuando el Tribunal cree oportuno devolver a juez de igual grado o superior (si es de distinto grado) y al competente si fué un Juez especial el que sentenció.

Podemos entender perfectamente las razones que tiene para fallar en estos dos sentidos si consideramos con Carnelutti que su procedimiento usa dos apelaciones, la primera libre, e ilimitada como nosotros y la segunda que tiene como fases el "iudicium rescinden" en el procedimiento de reenvío (rinvío).

El juicio rescisorio tiene pues como objeto en general la sustitución de la sentencia (iudicium rescissorium) y como objeto especifico, determinar "si subsiste el hecho y fué comelido por el inculpado para llegar a la fórmula de absolución prescrita çe que el hecho no ha existido o no fué cometido por el condenado, o de que falta totalmente la prueba de la comisión del hecho o de haberlo sido por el condenado". La determinación de esto es indispensable para que la anulación de la sentencia 
(iudicium rescinden) sea definitiva. El juicio rescisorio se desenvuelve según las reglas generales, excluyéndose de él naturalmente, a los condenados por falsedad (testigos, peritos, intérpretes) admitiéndose nuevas pruebas y con asistencia de la parte civil y de la civilmente responsable. El juez pues se encuentra en el dilema de: confirmar la sentencia o absolver. No cabe otra solución.

Ahora bien, la absolución no debe basarse exclusivamente en una nueva valorización de las pruebas del juicio precedente. Se debe acudir a la fuente de los hechos para proveer como es necesario dada la naturaleza de la institución y añade Florián que sería ilícito admitir atenuantes o excluír agravantes. La sentencia absolutoria es impugnable en casación por el Ministerio Público, correspondiente al Tribunal Supremo examinar sobre esto. En cambio la sentencia confirmatoria no es susceptible de ningún recurso.

Los efectos de la sentencia desestimatoria, y de la que no admite el recurso consisten en el pago de una multa fuerte, salvo en ciertos casos en que lo mismo que la confirmatoria sólo obliga al pago de las costas. No impidiendo estas sentencias el planteamiento del recurso por causales diferentes.

En el caso de anulación de la sentencia impugnada sus efectos son: 1) la liberación definitiva de la pena y de sus accesorios, como las medidas de seguridad, etc., 2) la proclamación de la inocencia y como complementos la reparación moral que se realiza mediante la publicación de la sentencia, la restitución al condenado de lo desembolsado con motivo de la condena, tal como las multas, costas, manutención penitenciaría, daños y medidas de seguridad patrimoniales y por último la reparación pecuniaria por el Estado que veremos en capítulo posterior.

En los casos que el condenado ha fallecido en establecimiento penal, reclama Florián la anotación marginal en su partida de defunción de la habilitación de su memoria.

Otros opinan porque la variación en la resolución del órgano decidente debe estar estrictamente de acuerdo con las situaciones permitidoras de la revisión y asi Castellanos quiere que en el caso de sentencias contradictorias la resolución declare la nulidad de ellas y ordene nueva instrucción. En el caso de supervivencia de la víctima de un homicidio y de que el raptor dé cuenta del paradero de la persona désaparecida o robada o aparezca ésta opina en líneas generales por la "nulidad del fallo y que se decida en derecho lo correspondiente", reclamando nulidad de la sentencia impugnada y nueva instrucción en el caso de documentos declarados falsos según sentencia firme en causa criminal.

Las mismas formas declarativas adoptan los tratadistas españoles salvo para la causal añadida por la ley Azcárate dada en 1933 que contempla el advenimiento de nuevos hechos posteriores a la sentencia $y$ que evidencian la inocencia del condenado.

Para este caso, piden que se reúna una información supletoria de la que dará vista el Fiscal y si resulta evidente la inocencia del condenado se procederá en la forma prevista, es decir, anulación de sentencia y orden de nueva instrucción.

Alcalá Zamora exige que en el caso de supervivencia de la víctima de un homicidio se ponga al condenado en inmediata libertad lo mismo 
que en el caso de documentos decisivos ignorados, extraviados o detenidos por fuerza por la acusadora, y si en este caso no se concede libertad se debe fijar una pena menor.

Para poder emitir una opinión respecto de la forma como el órgano competente debe dictar sus fallos en esta materia tendremos presente que la anulación de los fallos en virtud del recurso de revisión implica el proferimiento de otros, pues de todas maneras ha de resolverse el asunto principal, ésta debe ser pues la base sobre la que debemos exponer nuestra tesis.

Pero, aún antes no podemos dejar de hacernos la pregunta siguiente, ¿y en el caso de que no haya lugar a anulaeión? Vemos que la clasifjcación de Florián es la más acertada, en general sólo tres posibilidades tiene el fallo del organismo decidente; la inadmisibilidad, que de primera intención emite en la falta de las condiciones y requisitos exigidos para que pueda ser interpuesto el recurso, al margen de su buen éxito; la desestimación en la que una vez que se escucha los informes de los miembros encargados de esto se declara que no tiene fundamento suficiente el recurso como para dar lugar a la tercera clase de fallo o sea la declaración de la anulación de la sentencia condenatoria.

Declarada esta anulación, ¿debe procederse o no a una nueva instrucción? ¿Es posible que para algunos casos se ordene nueva instrucción y para otros nó?

A nuestro parecer, el estudio etimológico y luego la naturaleza de la revisión dan a entender que se trata materialmente de una nueva visión del proceso debido a uno o varios errores de hecho que han dado lugar a una sentencia injusta y a la condena de un inocente.

De esto desprendemos que siempre debe el fallo que ordena la anulación de la sentencia de cuya revisión se trate, comprender la ordên de apertura de nueva instrucción y nunca puede la revisión dar lugar a una condena que rebaje la pena impuesta anteriormente.

No se trata hemos visto de un recurso que tenga por objeto corregir la spreciación del juez o la valorización que se haya hecho de las pruebas presentadas y que emite en la sentencia traduciéndose en la condena, sino que su fin preciso es anular la sentencia y por lo tanto sustituirla por otra que en vista de los errores de hecho que originaron la anterior beneficie al condenado acreditando su inocencia y rehabilitándolo ante la sociedad.

No estamos tampoco de acuerdo en que la nueva sentencia pueda comprender el señalamiento de una pena rebajada, la revisión debe dar lugar a la absolución del inocente y no a una mera variación de la pena, su origen, su naturaleza y su objeto así lo exigen y lo extraordinario de su formalidad procesal que exige las seguridades en su uso reafirman y consolidan las ideas que exponemos.

Queda por terminar las cuestiones referentes a los efectos de dicha sentencia absolutoria, confirmatoria, desestimatoria o de inadmisibilidad en su caso.

Lógicamente el primer efecto será la liberación definitiva del condenado, de acuerdo con la tesis que sostenemos, pero el problema tanto de los efectos jurídicos de la sentencia anulada por la impugnación como de la nueva sentencia, y de lo referente a la libertad del recurrente durante el nuevo juicio los trataremos en el capítulo siguiente. 


\section{9. - EFECTOS JURIDICOS DE LA ANULACION DE LA SENTENCIA IMPUGNADA}

El primer efecto es como hemos repetido anteriormente la liberación definitiva de la pena y de sus accesorios, como medidas de seguridad, etc.. Y durante el juicio de revisión conviene tener presente que no se debe considerar al recurrente como condenado pues ha dejado de serlo desde el momento en que se anulá la sentencia impugnada y en cambio debe considerársele como un mero acusado o inculpado y por lo tanto con derecho a los beneficios en materia de libertad que la ley le otorga. Este debe ordenarlo el Tribunal Supremo que conoce del recurso. En Italia se exige para la admisibilidad de los recursos que interpongan los procesados evadidos u ocultos, contra la condena a ciertas penas, la presentación de dichas personas ante la autoridad penitenciaria y ello como condición indispensable. La razón salta a la vista, fácil sería pedir la revisión en esta forma para quienes no demuestran su convicción de inocentes mediante la presentación ante los jueces con la seguridad de ser absueltos. La desobediencia de la orden de detención nersonal no puede amparar a quienes pretenden abusar en esta forma de una institución establecida en beneficio de los condenados pero para ser escarnio de la justicia.

En el primer caso que hemos planteado o sea la libertad a raíz de la anulación de la sentencia impugnada, la detención posterior, dice Florián, no podría ser determinada más que por la transformación de la sentencia en cosa juzgada, lo que no sucede desde el momento en que se ha admitido el recurso y remitido la causa a nuevo Juez.

En cuanto a la proclamación de la inocencia este efecto se produce únicamente con la absolutoria del nuevo proceso y no conviene confundirla como algunos autores lo hacen con la declaración de no condenado contenida tácitamente en la anulación de la sentencia. El nuevo inculpado no tiene una declaración de inocencia sino un retiro de la condena señalada en la sentencia anulada, pero con la posibilidad de serle confirmada ésta, o declarada aquella.

Otro de los efectos de la sentencia recaída en el proceso de revisión es la reparación moral, cuya forma práctica es la publicación de la sentencia absolutoria por la que se acredita su inocencia, y a la que podríamos dar como razón de ser las palabras con que la famosa ejecutoria de 10 de julio de 1926 del Tribunal Supremo español resolvía el caso de Valero y Sánchez, conocido también como el caso de Osa de la Vega, (Acero y Jiménez de Asúa) "repugna a la conciencia negar a quien injustamente cumplió la condena la íntima satisfacción de verse rehabilitado como necesaria recompensa a su inmerecido infortunio".

La rehabilitación en el caso de condenado puede consistir en la anotación marginal en su partida de defunción, en el caso de que haya fallecido en un establecimiento penal. No hay mayores objeciones a la aceptación de estos efectos que nacen, digamos así, del aspecto meramente afectivo y que es el de más valor para la obtención del recurso. Pero al lado de estos efectos, está la cuestión de las reparaciones pecu- 
niarias que debe percibir el absuelto o sus herederos en su caso. Es el problema de las indemnizaciones.

Es por un espíritu de justicia, como expresa García Valdez, que la sociedad que ha causado a un individuo el enorme daño de privarlo de su libertad y de las ventajas y beneficios que con ella hubiera percibido, en el momento de reconocer su gravísimo aunque humano error, trata por todos los medios a su alcance de borrar todo el daño posible y aún de colocarlo en la vida social a la que se le restituye, con las mísmas posibilidades y las mismas oportunidades que hubiera estado antes y tratando de que no menoscabe su situación de penosa prueba sufrida.

Ya en el Ć́digo Penal de Marina español de 1888 se encuentra contemplada la indemnización a las víctimas de error judicial y la ley que adiciona el art. 960 de la ley adjetiva criminal de ese país, lo enuncia sin vacilación "cuando en virtud del recurso de revisión se dicte sentencia absolutoria, los interesados en ella o sus herederos tendrán derecho a las indemnizaciones civiles a que hubiere lugar según el derecho común, las cuales serán satisfechas por el Estado, sin perjuicio del derecho de éste de repetir contra el juez o Tribunal sentenciador que hubiere incurrido en responsabilidad, o contra la persona directamente declarada responsable o sus herederos".

Dos son las ventajas que ofrece este sistema: 1) la fijación de la indemnización según el derecho común, o sea en la vía civil cuyas apreciaciones se acercan más a lo normal en este aspecto que en la vía penal, y 2) la satisfacción de ella directamente por el Estado que asegura su facilidad, con las relatividades del caso, pero que evita un penoso litigio con el directo responsable, fuera del problema de la ubicación y determinación precisa de éste. Es así como apoyamos este sistema por considerarlo más efectivo y seguro, sobre todo si se tiene presente la ausencia total de este aspecto en nuestro flamante Código, lo que trataremos en próximos capítulos. El sistema italiano de restituir al condenado lo desembolsado como consecuencia de la condena o sea multas, costas, etc., nos parece que debe ser incluído en forma global en la indemnización a cargo del Estado, su detallismo extremo puede dar origen a dificultades y retardos innecesarios y que atenta contra el mismo objeto de la reparación pecuniaria o sea la más rápida y efectiva readaptación a la sociedad de un elemento injustamente separado de ella.

La trasmisión hereditaria de estos derechos no es negada ni contradicha pues forma parte del patrimonio del causante y el daño proveniente de la injusticia afecta por igual a éste y a sus sucesores.

Cabe aún preguntar, ila indemnización pecuniaria puede dar lugar a la aparición del oficio de "delincuente fingido" profetizado por Garófalo? No lo creemos así, la estricta aplicación de la ley filtra en sus requisitos toda falsa reclamación y las pocas que podrian escapar justifican el sistema pues no pueden pesar seriamente en el ánimo de. un legislador para hacerlo opinar en contrario.

$\mathrm{Y}$ con esto hemos terminado lo referente al análists de la institución en sí y en suj aspectos más importantes: entendida en esta forma la revisión, daremos una ojeada a su evolución histórica y decimos asi 
porque sus antecedentes en el tiempo son escasos, sólo en cuanto la consideremos como recurso impugnativo podemos rastrear su origen en la época romana.

\section{0. - ESQUEMA HISTORICO DEL RECURSO DE REVISION EN MATERIA PENAL}

La escasa bibliografía sobre este aspecto de la revisión dificulta la confección de un capítulo sobre la Historia de la revisión, por ello nos remitimos a un esquema que permita su ubicación y desenvolvimiento en el tiempo.

En la época romana se tenían dos conceptos de vicios frente a la sentencia judicial (Calamandrei, citado por Alcalá Zamora y Levene). Uno era el de la inexistencia de la sentencia cuando había sido pronunciada con falta de alguno de sus presupuestos esenciales y corresponde a la nulidad absoluta de nuestra época. El otro era el de la impugnabilidad que dá la pauta del comienzo de este aspecto actual de las resoluciones judiciales y que aparecía en cuanto existía falta de relación entre la sentencia y el derecho material.

Esta opinión nos parece ser la verdadera, pues la cita de Ulpiano (Digesto 49, I prima) desmiente la afirmación de Florián de que sólo se tienen "noticias incompletas", naturalmente que no se tiene un texto completo y que abarque la figura íntegra pero es posible hallar las disposiciones y conceptos que han dado origen a estas figuras.

Pasa en idéntica forma hasta la aparición de los derechos provinciales en los nuevos estados que se formaban a base de las antiguas provincias romanas y es así como el Derecho Longobardo trasplanta a Italia el criterio germánico que toma la impugnabilidad y descarta la inexistencia lo cual es un absurdo desdoblamiento de la bilateralidad maestra enunciada por los romanos, pero con el resurgimiento del Derecho Romano en Italia se combina el concepto germánico de la validez formal de la sentencia con la primitiva noción que dá lugar a los dos vicios.

En el balance se puede apreciar que del Derecho romano toman la noción de la existencia de unos vicios de mayor gravedad que otros pero pierden el concepto de que el vicio grave genera la inexistencia; en cambio del Derecho germánico se toma el concepto de que todo vicio genera la impugnabilidad y se deja la idea de que para todos los vicios haya una sola vía. El Derecho canónico sigue fielmente el romano, añadiéndole características especiales, que no son conocidas por el germánico.

Alcalá Zamora fija el origen del recurso en dos figuras: 1) la querela nullitatis insanalilis y 2) la restitutio in integrum. La primera se refiere a nulidades del procedimiento y de la sentencia a diferencia de "la sanabilis" que tiene plazo y se fundió con la apelación dando lugar al recurso de casación. La restitutio in integrum procede cuando ha habido falla en la defensa o aparecen nuevos elementos de decisión.

Esto ha dado lugar a dos tipos de revisión: 1) el francés, basado en la retitutio in integrum y que es seguido por el derecho canónico lo mismo que en Italia, España, Argentina, Perú, etc. (En los Códigos de 
Córcloba y Santiago del Estero, Argentina, se sigue la versión española, y 2) el germánico, en el que se admite la acción de nullidad sólo en lo civil.

En España tiene su primera referencia (según García Valdez) en la ley de las Partidas que preceptuaba que "todo juicio que fuese dado por falsos testigos o por falsas cartas o por otra falsedad cualquiera, o por dinero 0 por don que hubiera corrompido al juez; aunque contra quien fuese dado no se alzare de él, lo puede desatar cuando quiera hasta veinte años probando que el juicio primero fué dado por aquellas pruebas o razones falsas", lo que demuestra la extraordinaria previsión del legislador.

Esto rigió hasta el Reglamento de 30 de diciembre de 1846 que lo refiere a lo contencioso administrativo, siendo ampliado a lo civil posteriormente y a la ley adjetiva penal como recurso extraordinario, habiendo tenido eficaz aplicación en varios famosos casos como el de Osa de la Vega (1926) narrado por Jiménez de Azúa y comentado por él en una serie de artículos titulados "Los errores de la Justicia".

La configuración que le dió el derecho francés prima hoy en la mayoría de los códigos y como dice Alsina, creemos que la tendencia actual se orienta, no a la supresión sino al condicionamiento de los medios de impugnación y por eso afirmamos anteriormente que la admisión de recursos debe restringirse con la paralela exigencia de requisitos y condiciones que aumentan hasta culminar con la revisión.

\section{1. - LEGISLACION NACIONAL Y CRITICA}

Para nuestro Código de Procedimientos en Materia Criminal fué una gran conquista la inclusión del recurso de revisión y en su Exposición de Motivos se justifica esto al expresar que "la cosa juzgada en los juicios civiles puede ser absoluta, pero no lo puede ser respecto de la condena que pesa sobre un inocente". La cosa juzgada no es aplicable a la pena. El derecho a la inocencia es inalienable, imprescrliptible, inviolable. La condena que pesa sobre el inocente desde el momento que se descubre el error, es un crimen flagrante, el más infame y el más alevoso de todos los crímenes. No hay consideración alguna que pueda permitir que se consume. Los casos de revisión que hemos aceptado son los que consignan todos los códigos cuando la supervivencia de la supuesta víctima, el descubrimiento del verdadero culpable o la falsedad de la prueba aparecen después de la sentencia". En realidad fué una "importante conquista" como la llama Calle.

Se le incluyó en el libro III que trataba de los procedimientos especiales y a nuestro juicio esto fué un error pues si bien es cierto que su tramitación tiene características especiales, se trata en el fondo de un recurso de categoría extraordinaria y como este aspecto prima sobre el formal debió incluírsele en el libro II que trataba del juicio y a continuación del título $\mathrm{V}$ que se ocupaba del recurso de nulidad.

Sus causales tomadas del sistema español y del francés abarcan cuatro casos y tienen el mérito en primer lugar de referirse textualmente a la sentencia condenatoria con exclusión de cualquier otra; en segundo lugar el inciso $4^{\circ}$ tiene un carácter de generalidad que lo hace aparecer avanzado frente a la legislación positiva que dió origen al 
artículo y la que sólo incluyó esta cuarta causal a raíz de la mencionada ley Azcárate de 24 de junio de 1933.

Fijaba este código como personas que podían interponer el recurso al condenado ("acusado" por error en el texto) y parientes en los tres primeros casos y en el cuarto, sólo los Fiscales podían hacer uso del recurso. Este error obligaba naturalmente al apersonamiento del interesado ante el Fiscal correspondiente para pedirle verbalmente que interpusiera el recurso en su caso, lo que no se ha mantenido en el novísimo Código como veremos.

El código actual vigente desde el 18 de marzo de 1940, indica como causales las siguientes: 1) Cuando después de una condena por homicidio se produzcan pruebas suficientes de que la pretendida víctima del delito vive o vivió después de cometido el hecho que motivó la sentencia; 2) Cuando la sentencia se basó principalmente en la declaración de un testigo condenado después como falso en un juicio criminal; 3) Cuando después de una sentencia se dictara otra en la que se condene por el mismo delito a persona distinta del acusado, y no pudiendo conciliarse ambas sentencias, de su contradicción resulte la prueba de la inocencia de alguno de los condenados; 4) Cuando la sentencia se haya pronunciado contra otra precedente que tenga la calidad de cosa juzgada y 5) Cuando con posterioridad a la sentencia se acrediten hechos por medio de pruebas no conocidas en el juicio que sean capaces de establecer la inocencia del condenado".

Añade pues una causal más basada en la excepción de cosa juzgada. Acertacamente critica el catedrático de la Universidad Católica, Dr. Vargas Mata, el inciso $4^{9}$, calificándolo de "oscuro" por cuanto implica una repetición de lo indicado en el 3er. inciso y además le reprocha el no considerar que el primer condenado podría a su vez interponer el recurso amparándose en que la segunda sentencia condenando a otra persona acreditaría en forma evidente su inocencia.

El inciso comentado "beneficiaría a ambos" y su éxito estaría de parte de quien lo interpusiera con primacía en el tiempo. Es una redurdancia que se debe eliminar.

En cuanto al inciso quinto, nos parece que abarca todos los demás pues de acuerdo con su texto, nadie puede negar que la supervivencia de la pretendida víctima de un homicidio, la condena de un testigo por falsedad o la sentencia contradictoria, posteriores a la sentencia materia de revisión, son "pruebas no conocidas en el juicio y capaces de estabiecer la inocencia del condenado".

Nuestia opinión es que la reforma deseable en este aspecto debe comprender una generalización de las causales en un solo enunciado. INo es de temer el abuso o exagerada interpretación o aplicación de él si se tiene cuidado de exigir los requisitos de inocencia evidente, claridad y facilidad de apreciación del nuevo hecho o prueba aportando lo que queda tamizado por la atribución del Fiscal de informar y dictaminar solne la solicitud.

Proponemos, tomaria lo expresado en el capítulo pertinente, que la fórmula sea más o menos del tenor siguiente:

"La sentencia condenatoria deberá ser revisada por la Corte Suprema, cualquiera que sea la jurisdicción que haya juzgado o la pena que haya sido impuesta: 1) cuando exista prueba evidente, no conocida 
en el juicio de que no se realizó el hecho que motivó la condena; y 2) cuando exista prueba evidente, no conocida en el juicio, de la inocencia del condenado".

La fundamentación detallada aparece en el capítulo 5 de este estudio que trata de los motivos de la revisión.

En cuanto a las personas que pueden interponer el recurso estamos de acuerdo con lo estipulado en el código lo mismo que en lo referente al procedimiento.

Por un error imperdonable el código no se ocupa de la indemnización de las víctimas de error judicial, es una omisión que precisa subsanarla.

Pensamos en que la mejor forma sería añadir al código una disposición que podría reproducir lo contenida en la ley Azcárate, cuyos beneficios fijamos en la parte en que discutimos este aspecto.

Dice así: "Cuando en virtud del recurso de revisión se dicte sentencia absolutoria, los interesados en ella o sus herederos tendrán derecho a las indemnizaciones civiles a que hubiera lugar según el derecho común, las cuales serán satisfechas por el Estado sin perjuicio del derecho de éste de repetir contra el Juez o Tribunal sentenciador que hubiere incurrido en responsabilidad o contra la persona directamente declarada responsable o sus herederos".

$\mathrm{Y}$ así terminamos el estudio de la legislación nacional y su crítica que no fundamentamos extensamente por cuanto al tratar de la figura en general hemos expuesto nuestra opinión respecto de cada punto tratado con las argumentaciones que consideramos nos apoyan.

\section{2. - CONCLUSIONES}

1) Es admisible, moral, jurídicamente y prácticamente la revisión de las sentencias penales.

2) La revisión es un recurso extraordinario y voluntario establecido en beneficio del condenado.

3) La revisión sólo debe concederse respecto de las sentencias condenatorias.

4) Las causales de la revisión son: 1) La prueba evidente, no conocida en el juicio de que no se realizó el hecho que dió origen a la sentencia impugnada, 2) La prueba evidente, no conocida en el juicio, de la inocencia absoluta del condenado.

5) Pueden interponer el recurso, el condenado, sus parientes en el grado fijado por la ley, sus herederos y el Ministerio Público.

6) La revisión debe seguirse según un procedimiento especial ante el Tribunal Supremo desdoblado en función instructiva y resolutoria.

7) El fallo del Tribunal Supremo debe declarar: 1) la inadmisibilidad, o 2) la desestimación, o 3) la anulación de la sentencia impugnada y la orden de nueva instrucción, la que a su vez culminará con fallo confirmatorio de la impugnada o absolutorio del recurrente.

8) La sentencia absolutoria tiene como efectos: 1) la libertad definitiva del recurrente, 2) la rehabilitación moral, y 3) la indemnización pecuniaria por el Estado sin perjuicio del derecho de éste de repetir contra los responsables.

9) Nos parece que el art. 361 del C. de P.P. vigente debería ser modificado, proponiendo la fórmula siguiente:

"La sentencia condenatoria deberá ser revisada por la Corte Suprema, cualquiera que sea la jurisdicción que haya juzgado o la pena que haya sido impuesta: 1) cuando exista prueba evidente no conocida en el juicio, de que no se realizó el hecho que motivó la condena, y 2) cuando exista prueba evidente no conocida en el juicio, de la inocencia del condenado". 


\section{3. - BIBLIOGRAFIA}

E. Ferri.-Nuevos horizontes del Derecho y el Procedimiento Penal. Traduc. Isidro Pérez Oliva.

Icilio Vanni.- Filosofía del Derecho.

García Moreno y Regules.- Instituciones politicas y jurídicas de los Pueblos Moldernos.

Carnelutti.- Instituciones del nuevo proceso civil italiano.

Florián.- Elementos de Derecho Procesal Penal.

Carlos Castellanos.- Curso de Procedimientos Penales Guatemala 1938.

Rafael de Pina.- Manual de Derecho Procesal penal. Sevilla.

J. Acero.- Nuestro Procedimiento Penal. México.

Alcalá Zamora y Levene.- Derecho Procesal Penal.

Rafael Garcfa Valdez.- Derecho Procesal Oriminal. España.

J. J. Calle.- Código de Procedimientos en Materia Criminal. Lima.

Espasa.- Enciclopedia Universal Ilustrada.

Manuel Urrutia Salas.- (Revista de D.P.A. Hugo Alsina 1945).

Gregorio Corellano.- Nociones de Procedimientos Penales. Argentina 1935.

Domirgo Giurati.- Los errores judiciales. Madrid.

F. Manduca. - El procedimiento penal y su desarrollo científico.

Vargas Mata.- Derecho Procesal Penal - Curso Universitario (U.C.)

Laurent.- Autoridad de la cosa juzgada.

Luis Jiménez de Asúa.- Los yerros de la justicia. "La Prensa" de Buenos Aires. 